DIGITALCOMMONS

@WAYNESTATE-
Michigan Journal of Counseling:

Research, Theory and Practice

Volume 31 | Issue 2

Article 5

$10-1-2003$

\title{
Response-cost: A Home System For Modifying The ADHD Child's Behavior
}

Paul Lavin

Norbel School

Follow this and additional works at: https://digitalcommons.wayne.edu/mijoc

\section{Recommended Citation}

Lavin, P. (2003). Response-cost: A Home System For Modifying The ADHD Child's Behavior, Dimensions of Counseling, 31(2), 25-30. doi: $10.22237 / \mathrm{mijoc} / 1064966640$

This In the Field is brought to you for free and open access by the Open Access Journals at DigitalCommons@WayneState. It has been accepted for inclusion in Michigan Journal of Counseling: Research, Theory and Practice by an authorized editor of DigitalCommons@WayneState. 


\section{In The Field}

\section{Response-cost: A Home System For Modifying The ADHD Child's Behavior}

\section{Paul Lavin, Ph.D.}

Paul Lavin, Ph.D. is a consultant with the Norbel School, a

facility in Maryland for ADHD and learning disabled youngsters.

Correspondence regarding this article can be sent to Paul Lavin,

Ph.D., 9 Park Drive, Catonsville, MD 21228.

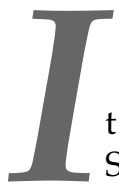

$t$ is estimated that $3 \%$ to $5 \%$ of children in the United

States are diagnosed with Attention Deficit

Hyperactivity Disorder (American Psychiatric Association, 1994) or ADHD as it is commonly known. There is also evidence indicating that untreated and under treated children with ADHD are at high risk for long-term academic, social, and psychological problems (Erk, 2000; Schweibert, Sealander, \& Dennison, 2002). The role of the school counselor as a consultant to the parents of such children is well documented in the literature (Lavin, 1991; Gomez \& Cole, 1991; Kottman, Robert, \& Baker, 1995; Lavin, 1997, Lavin, Gold, \& Dellarose, 2000).

Due to the counselor's psychological training and knowledge about those dynamics influencing human behavior, he or she would be the most logical school staff member to assist parents in understanding and treating ADHD. This task can be particularly challenging when the counselor is asked to help parents who have been unsuccessful in their attempts to modify their child's behavior. For example, the use of positive reinforcement, a behavior modification system in which points, tangible rewards, and / or privileges are given following appropriate behavior, has clearly been shown to be effective in the treatment of ADHD (Goldstein \& Goldstein, 1990; Gomez \& Cole, 1991; Lavin, 1991; Barkley, 1998; Lavin, Gold, \& Dellarose, 2000). However, there are some children with ADHD who fail to respond to this approach. Despite being given many opportunities to earn valuable rewards, they consistently behave poorly. For parents, who have been unsuccessful with this system, this can be a particularly harrowing experience. The challenge for the school counselor, therefore, is to 
help these parents to devise an alternative behavior modification program that can be effective in improving their child's behavior.

The purpose of this article is to present such an alternative approach. The Norbel School Home Response-Cost Behavior Modification Program is an experimental program currently being field tested at Norbel School in Elkridge, Maryland. Norbel is an educational facility that specializes in working with students who have ADHD and are learning disabled. The Response-Cost Program was developed to help those parents whose children were having ongoing behavior problems at home and school and had been unresponsive to those behavior modification systems using positive reinforcers as incentives for behavioral change.

The rationale for the development and use of a response-cost system is based on research results showing that this approach is particularly effective with children with ADHD who have become chronic behavior problems (Kaufman \& O'Leary, 1972; Rapport, Murphy, \& Bailey, 1980; Rapport, Murphy, \& Bailey, 1982; Rapport, 1987; Goldstein \&Goldstein,1990; Carlson, Mann, \& Alexander, 2000). Since many children with ADHD have marked difficulty with self-control, they are unable to sustain the needed effort to earn rewards that are contingent on first behaving appropriately. As a result, they often develop a pessimistic attitude, believing that no matter how hard they try, it is unlikely that they will perform successfully (Michenbaum, 1977; Linn \& Hodge, 1982; Miranda \& Prentacion, 2000). Due to their poor prior reinforcement history, many children with ADHD do better when they are required to behave appropriately to keep their privileges instead of having to earn them. Despite the success of response-cost, however, programs that train parents to put this into practice in the home situation do not appear in the literature. Rather, responsecost has mostly been implemented in various classroom settings (Sprute, Williams, \& McLaughlin,1990; Proctor \& Morgan, 1991; Kotlin, 1995; Barkley, 1996; Barkley, 1998). What makes the Norbel School's approach unique is the attempt to use those behavioral principles upon which response-cost is founded and apply them in formulating a program that parents can use in the home setting.

\section{How Response-Cost Works}

Response-cost is a behavior modification system that utilizes negative reinforcement and punishment. Both of these have aversive consequences attached to them. With negative reinforcement, the frequency of desirable behavior increases in order to avoid the application of such consequences. In punishment, on the other hand, the aversive consequences are applied in order to stop an ongoing inappropriate behavior. In applying this to response-cost, the child with ADHD is first provided with the full range of privileges without having to earn them. As long as he or she behaves appropriately, the child is allowed to keep these. Should a rule violation occur, however, a punishment would be applied. This would entail taking away all or some privileges, depending on the seriousness of the offense. Hence, we have the system of response-cost put into practice. If the child responds positively, no cost for privileges is incurred. However, if the child's response is inappropriate, then a negative cost or retribution is attached to it.
While an extremely serious offense may incur the temporary loss of all privileges, these are immediately reinstated once restitution has been made. For less serious violations only some, not all, privileges are taken away. Keeping the remaining privileges can, therefore, serve as an incentive for recovering and preventing further deterioration. Because response-cost provides the child with ADHD with the opportunity to quickly regain selfcontrol, he or she is more likely to develop a more positive attitude. A more optimistic outlook increases the likelihood that the child will persist instead of becoming discouraged when challenges arise.

\section{The Benefits of Response-Cost for Parents}

For parents, the benefits of response-cost are many. First, response-cost is easy to use (Barkley, 1998). It requires much less record keeping than that of a positive reinforcement program. For working parents who are on a time limited schedule, this can be a major benefit. Second, because inappropriate behavior is disruptive, parents usually more readily attend to it. This, in turn, makes it more likely that immediate and consistent consequences will be applied, and that inappropriate behavior will cease.

Third, response-cost requires that the consequences for violations be determined before these occur. This assures that disciplinary over-reactions, complaints about 


\section{Figure 1 \\ Steps in Implementing Home Response-Cost Behavior Modification Program}

(1) Explain behavioral principles of response-cost to parents

(2) Construct the program

(a) Identify daily, weekly, and long-term rewards

(b) Identify behavioral violations leading to loss of rewards

(c) Categorize violations as extremely serious, very serious, or serious

(d) Determine loss of rewards associated with each violation

(3) Explain response-cost program to ADHD child

(4) Put the program into practice.

unfairness, power struggles, and family disruptions can be minimized and even avoided. And fourth, responsecost provides immediate, ongoing incentives for motivating the child with ADHD. This increases the likelihood that an improvement in appropriate behavior will occur. More importantly, however, this behavioral improvement proves to the child with ADHD that he or she is capable of performing successfully provided that the child is willing to make the effort to do so. As a result, the youngster is more likely to develop a better selfconcept and improved relationships with peers and adults.

\section{Preparing Parents for Response-Cost}

In order to help parents to understand the behavioral principles on which the response-cost program is based, explanations are provided by the Norbel School staff. See Figure 2 for a sample explanation.

After, explanations have been provided, it is important to make sure that parents understand the similarities and differences between punishment and negative reinforcement and how to apply these in modifying the child's behavior. We then address any questions that they might have and provide further examples if needed. Once the preceding has been completed, the next step is to explain the basic rudiments of setting up the actual program. Again, parents are given the opportunity to ask questions. A further explanation and more specific examples might be needed to clarify how the system works. Once these have been successfully mastered, the actual construction of the program can begin.

\section{Constructing the Response-cost Program}

As noted earlier, the first step is to identify all rewards that might serve as potential incentives for bringing about appropriate behavior. Both parents and the child might work together in constructing this list. The rewards are then placed in one of three categories: daily rewards, weekly rewards, and long-term rewards. Daily rewards are those that are available to the child on each day of the week. Examples are as follows: television viewing, radio, video games, stereo, telephone use, snacks, staying up beyond bedtime, playing a game with parent, ride bike, soft drink, friend over to play, draw, paint, or make crafts. The daily rewards are provided within limitations set by the parents. For instance, the child might be restricted to one soft drink a day or one hour of playing video games. A list of daily, weekly, and long-term privileges should be posted on a bulletin board or in a place in which the child can see them.

\section{Figure 2 \\ Explanation to parents}

The purpose of response-cost is to provide you with a program that will help you to improve your child's behavior. There are two principles that you need to understand in implementing this approach. Punishment and negative reinforcement are applied together in a response-cost program. While both punishment and negative reinforcement rely on the use of aversive or unpleasant consequences, negative reinforcement brings about an increase in appropriate behavior. Punishment, on the other hand, stops obnoxious or inappropriate behavior. For example, Johnny enjoys watching his favorite television program with the family. This is a privilege that his parents have given him provided that he behaves appropriately. Unfortunately, on one of the evenings, Johnny behaved poorly while the family was watching television together. Johnny was sent to his room. He missed his favorite television program. Because this was so unpleasant, Johnny stopped behaving inappropriately. Johnny did not want to be sent to his room again. The punishment of being confined to his room stopped his disruptive behavior. Now, while watching television with the family, Johnny behaves quietly and respectfully. He wants to avoid being sent to his room in the future. The threat of being sent to his room (the previous punishment) is now a negative reinforcement. Why? The former punishment is responsible for motivating Johnny to behave appropriately when he is with the family watching television. From this example, you can see how punishment and negative reinforcement work together in order to bring about improved behavior. 
If the child commits no violations for the week, a weekly privilege can be made available to him or her. These would be provided on the weekend as long as the child continues to behave appropriately. Examples of weekly privileges are as follows: trip to a fast food restaurant, going to the library, a special desert, visit a friend for the day, allowance for the week, a friend over night, go to friend's house over night, pizza, order a special meal at home, roller skating, ice skating, movie, visit grandparents for the day, stay up late for the weekend. Again, the availability of these would be determined within limitations set by the parents. As an incentive for maintaining appropriate behavior for an extended period of time, it is important to insure that special weekend privileges are available for a week of no violations serves. This leads to the development of better work habits. These then replace the inattention and impulsivity that previously plagued the child with ADHD.

If the child commits no violations for two weeks or longer, even more desirable privileges might be made available.

Examples of these are as follows: go to an expensive restaurant, buy a video game, buy a ten dollar toy, go fishing, go to a professional sporting event, go to an amusement park, go on a picnic, camping, buy brand name clothing, take a friend to a ballgame or restaurant, go to an arcade, day trip to a place of the child's choice, go to the zoo. Long term privileges can be discussed in advance with the child. This will teach the child to think and plan ahead. Again, this is the antidote for inattention and impulsivity. No violations for long periods of time require extended effort on the child's part. This is what leads to the development and sustaining of better behavioral habits.

Once the rewards have been determined, then all inappropriate behavior that could result in their loss should be identified and put into one of three categories: extremely serious, very serious, or serious. It is explained to the child that if he or she behaves inappropriately, then one, two, or more of his privileges can be taken away. How many of these that would be lost is determined by the seriousness of the offense.

Extremely Serious Offenses. Extremely serious offenses are those in which the rights of others are violated. These may result in damage to or the loss of property, injury to other persons, or a major inconvenience to those who are responsible for caring for the child. Extremely serious violations require that the child does the following: (1) apologize for the violation; (2) make restitution for the loss, damage, or injury; and (3) pay a "fine" or perform community service. With regard to the latter, the child might donate five dollars to a charity or he or she might pick up trash around the school for a week. If an extremely serious violation occurs, all privileges for the day, week, or long term are suspended. Once the preceding restitution is completed, then all privileges are restored. Examples of extremely serious violations and what might be done to rectify them are as follows:

(1) Stealing from a store, parent, or member of the community:
(a) return or pay for the item;
(b) apologize for stealing;
(c) perform a service for the inconvenience that this caused the victim.

(2) Destroying property:
(a) apologize to the property owner;
(b) fix or pay for the damage;
(c) perform a service for the institution or person whose property was damaged.

(3) Hitting or injuring another person:
(a) apologize;
(b) pay for any medical treatment (e.g. bandage, antiseptic, doctor's visit etc.);
(c) perform a service for the person.

(4) Cheating and lying:

(a) apologize to the person affected by the act;

(b) go to each person who might have believed the lie or who has been affected by the cheating and tell them the truth;

(c) pay back or perform a service to those whose life has been negatively impacted by the lie or cheating.

(5) School suspension:

(a) apologize verbally and in writing for the violation;

(b) make restitution to those affected;

(c) provide a service to those who have been inconvenienced. 


\section{Figure 3 Explanation to child}

If I stole something from a store, I would have to show that I was sorry for what I did by apologizing to the store owner. I would also have to pay for or return the stolen item.

Moreover, I would have to go to court. The judge would make me pay a fine, perform community service, or go to jail. Even if I apologized and paid for the item, this would not be enough. I would still have make restitution for the disruption that I caused to the store owner, the police, and the court. When you break an important rule, the same consequences must apply to you. This is only fair. This is why we are requiring that you do this. Once you complete your obligations, then all of your privileges will be restored.

In order that the child might understand the rationale for the preceding the parents must give clear explanations as demonstrated in Figure 3. Such explanations help the child to see that consequences are sensible and not arbitrarily applied. Moreover, it provides the child with ADHD with specifics as to when his or her privileges will be returned.

Serious Offenses. Serious violations are those in which a child fails to fulfill an obligation, to complete a task, or to comply with a parental request. However, the child, rather than other people, is inconvenienced by his or her inappropriate behavior. With a serious violation, the child is required to correct his or her mistake. Once this occurs, all privileges are immediately restored. As indicated earlier, a persistent failure to correct this behavior could become a very serious or extremely serious violation, depending on the inconvenience or damage to others that might ensue. Some examples of serious violations and the consequences that might be applied are as follows:

(1) Losing or forgetting homework: The child must make up the work. Then all privileges are restored.

(2) Pouting or refusing to talk when asked a question or spoken to: Ignore the child until he or she decides to respond. All privileges are restored when the chil responds appropriately.

(3) Fails to clean up room or pick up toys: All privileges on hold until the task is completed. The child could choose to have the parents pick up the toys. However, these then would become the parent's property to be kept by them and disposed of as they see fit.

(4) Child picks at food, eats too slowly, or exhibits poor table manners: Set a short time limit (e.g. one minute) to change this behavior. If this is not corrected, take away the food. No food is provided until the next scheduled meal. If this occurs in the evening, this means no food until the next morning.

(5) Child fails to dress or groom properly: The child is sent to bed early so that he or she can get enough sleep and have the energy and time to attend to these tasks in the morning. Once these tasks are completed, the original bedtime can be returned.

Should a serious violation occur, one or more, but not all, of the child's daily privileges are taken away. If the child discontinues the inappropriate behavior she would still have the right to the remaining privileges. Should the behavior continue, a suitable warning could be given before taking away another privilege. If the child persists in behaving inappropriately, all privileges are suspended for that day. The child's blatant failure to comply then becomes an extremely serious violation. This would require an apology and proper restitution for the offense. Once the child apologizes and makes restitution for the inconvenience that he or she caused, all privileges are restored on the following day. Again, this approach serves as an antidote to discouragement. It makes it more likely that the child will willingly cooperate with the program.

\section{Conclusions}

An important part of the school counselor's role is to consult with the parents of children with ADHD. As indicated previously, children with ADHD who are ignored or under treated are at high risk for experiencing academic, social, and psychological problems.

The school counselor's knowledge of the response-cost approach and its application can be particularly helpful to parents whose children with ADHD have failed to respond to the use of positive reinforcement programs and have become chronic behavior problems. The Norbel School response-cost program is currently being offered to parents whose children fall into this category. While no long-term data are yet available, the anecdotal evidence suggests that this is an effective alternative to other behavioral approaches that have been unsuccessful. Thus, a knowledge of response cost would be a significant addition to the school counselor's treatment armamentarium. 
It can be of much benefit in helping the school and parents to work together in improving the behavior of the most troubled children. The response-cost approach, as noted earlier, provides an ongoing incentive that encourages the ADHD child to cooperate with his or her parents and teachers. This ultimately leads to improved behavior and the development of better work habits. Moreover, it increases the probability that the ADHD child will receive positive feedback from parents, teachers, and peers. This, in turn, makes it more likely that good work habits and socially appropriate behavior will continue.

\section{References}

American Psychiatric Association. (1994). Diagnostic and statistical manual of mental Disorders (4th ed). Washington, DC: Author.

Barkley, R. (1990). Attention deficit hyperactivity disorder: A handbook for diagnosis and treatment. New York: Guilford. Press.

Barkley, R.A. (1998). Attention deficit hyperactivity disorder: A handbook for diagnosis and treatment (2nd Ed.). New York: Guilford Press.

Barkley, R.A., Shelton, T.L., Crosswait, C., Moorehouse, M., Fletcher, K., Barrett, S., Jenkins, L., \& Metevia, L. (1996). Preliminary findings of an early intervention program for aggressive hyperactive children. In C.F. Ferns \& T. Grisso (Eds.) Annals of the New York Academy of Sciences :Vol. 794. Understanding aggressive behavior in children. (pp.277-289). New York: Academy of Sciences.

Carlson, C.I., Mann, M., \& Alexander, D.K. (2000). Effects of reward and response-cost in the performance and motivation of children with AD/HD. Cognitive Therapy and Research, 24, 87-98.

Erk, R.R. (2000). Five frameworks for increasing understanding and effective treatment of attention-deficit/hyperactivity disorder: Predominately inattentive type. Journal of Counseling $\mathcal{E}$ Development, 78, 389-399.

Goldstein, S. \& Goldstein, M. (1990). Managing attention disorders in children. New York: John Wiley \& Sons.

Gomez, K.M. \& Cole, C.L. (1991). Attention-deficit hyperactivity disorder: A review of treatment alternatives. Elementary School Guidance and Counseling, 26, 106-114.
Kaufman, K.F. \& O'Leary, K.D. (1972). Reward, cost and self-evaluation procedures for disruptive adolescents in a psychiatric hospital school. Journal of Applied Behavior Analysis, 5, 293-309.

Kotkin, R.A. (1995). The Irvine paraprofessional program: Using paraprofessionals in serving students with ADHD. Intervention in School and Clinic, 30, 235-240.

Kottman, T., Robert, R., \& Baker, D. (1995). Parental perspectives on attention deficit hyperactivity disorder: How school counselors can help. The School Counselor, 43, 142-150.

Lavin, P. (1991). The counselor as consultant-coordinator for children with attention deficit hyperactivity disorder. Elementary School Guidance and Counseling, 26, 115-120.

Lavin, P. (1997). A daily classroom checklist for communicating with the parents of the ADHD child. The School Counselor, 44, 315-317.

Linson, R.T., \& Hodge, G.K. (1982). Locus of control in childhood hyperactivity. Journal of Consulting and Clinical Psychology, 50, 592593.

Meichenbaum, D. (1977). Cognitive behavior modification. New York: Plenum Press.

Miranda, A., \& Prentacion, M.J. (2000). Efficacy of cognitive behavioral therapy in the Treatment of children with AD/HD with and without aggression. Psychology in the Schools, 17, 169-182.

Proctor, M.A., \& Morgan, D. (1991). Effectiveness of response-cost raffle procedure on the disruptive behavior of adolescents with behavior problems. School Psychology Review, 20, 97-109.

Rapport, M.D., Murphy, H.A., \& Bailey, J.S. (1982). Ritalin vs. responsecost in the control of hyperactive children. A within-subject comparison. Journal of Applied Behavior Analysis, 15, 205-216.

Rapport, M.D., Murphy, A., \& Bailey, J.S. (1980). The effect of a responsecost treatment tactic on hyperactive children. Journal of School Psychology, 18, 98-111.

Rapport, M.D. (1987). The attention training system. DeWitt, NY: The Gordon Systems.

Schweibert, V.L, Sealander, K.A., \& Dennison, J.L. (2002). Strategies for counselors working with high school students with attentiondeficit/hyperactivity disorder. Journal of Counseling $\mathcal{E}$ Development, $80,3-10$.

Sprute, K.A., Williams, R.L., \& McLaughlin, T.F. (1990). Effects of group response and contingency procedures on the rate of classroom interruptions with emotionally disturbed secondary students. Child and Family Behavior Therapy, 12, 1-12. 